\title{
Compostagem de resíduos sólidos orgânicos como tema incentivador de educação ambiental
}

Composting of organic waste as incentive in environmental education

\author{
G. A. A. de Lima'; C. A. C. Dias ${ }^{1}$; A. H. Lima ${ }^{2 *}$ \\ ${ }^{1}$ Centro de Ciências Sociais e Educação, U niversidade do Estado do Pará, CEP 66810-010, São Miguel do Guamá- \\ Pará, Brasil \\ ${ }^{2}$ Instituto de Ciências Exatas e Naturais, Universidade Federal do Pará, CEP 66075-110, Belém-PA, Brasil
}

*anderson@ufpa.br

(Recebido em 20 de abril de 2016; aceito em 29 de abril de 2016)

\begin{abstract}
O presente trabalho diz respeito a uma prática ambiental promovida com a cooperação de alunos do ensino fundamental de uma escola localizada no município de São Miguel do Guamá - PA. Diante das constantes transformações que a sociedade passa ao longo dos anos, a poluição ambiental torna-se por vezes resultado de práticas inconscientes. Para tanto, torna-se necessária a aplicação de atividades sustentáveis também no âmbito escolar, pois nele encontram-se alunos em processo de formação. Neste sentido, o aproveitamento de resíduos sólidos orgânicos provenientes de merenda escolar foi utilizado na produção de adubo orgânico a partir de processo de compostagem e mostrou-se uma alternativa viável para o incentivo da Educação Ambiental no espaço escolar, levando os participantes, professores e alunos a serem agentes de boas ações no ambiente em que trabalham e estudam, colaborando durante o processo que culminou no reaproveitamento dos resíduos sólidos orgânicos gerados na instituição de ensino, onde o adubo ecologicamente formado pôde ser aplicado na horta feita a partir de materiais reciclados para benefício de todos. É importante ressaltar, que os trabalhos nesta área também auxiliam na construção de conhecimentos importantes no ensino fundamental.

Palavras-chave: Compostagem, Educação Ambiental, Prática Educativa.
\end{abstract}

This work shows the results from an environmental practice promoted with the cooperation of elementary school students from the city of São Miguel do Guamá - PA. Due to the constant changes in society over the years, environmental pollution becomes sometimes a result of unconscious practices. Thus, the implementation of sustainable activities is necessary also in schools once we have students in formation process. In this sense, the use of organic solid waste from school meals was used in the production of organic fertilizer using composting. This method proved to be a viable alternative to the encouragement of environmental education at school. Thus, it takes teachers and students to be good deeds agents at the place where they work and study, collaborating during the process of reuse organic waste generated in the educational institution. The ecologically formed fertilizer has been applied in the garden made with recyclates that benefit of all. It is important to note that work in this area also help to build important skills in elementary school.

Keywords: Composting, Environmental Education, Educational practice.

\section{INTRODUÇÃO}

O desenvolvimento socioeconômico e a evolução dos hábitos de vida acabam gerando um excessivo consumo de bens, o que conduz a degradação de recursos e a geração de uma grande quantidade de resíduos. A questão do lixo produzido nas cidades é, sem dúvida alguma, um imenso problema na maior parte dos municípios do Brasil [1].

Cada uma das frações de plásticos, vidros e metais participa com um décimo do volume do resíduo sólido em países em desenvolvimento como o Brasil. Enquanto que a fração relativa à matéria orgânica (restos de alimentos) representa cerca de dois terços desse valor [2].

Para buscar solucionar os problemas relacionados aos resíduos sólidos, como o não reaproveitamento da matéria orgânica gerada e o descarte inadequado acarretando poluição, 
torna-se necessária a inserção de práticas que propiciem a reciclagem como, por exemplo, a compostagem orgânica. $\mathrm{O}$ modelo gerencial de compostagem possui grandes vantagens, pois além de desviar resíduos do lixão a céu aberto, do aterro sanitário ou controlado, ainda promove uma nova utilização para a matéria orgânica [3]. Esta problemática está, intimamente, ligada a conscientização ambiental, que surge a partir do contato entre os educandos e os problemas que os cercam, onde a adoção de atividades ecológicas no âmbito escolar torna-se uma ferramenta indispensável na formação de cidadãos com uma visão crítica sobre as questões ambientais.

A educação ambiental é um processo pelo qual o aluno começa a adquirir conhecimentos acerca das questões ambientais, onde ele passa a ter uma nova visão sobre o meio ambiente, sendo um agente transformador em relação à conservação ambiental [4]. Os problemas ambientais, portanto, passam a ser considerados como fatos que precisam ser trabalhados com os indivíduos constituintes da sociedade. Nas escolas, a educação ambiental colabora para a formação de cidadãos conscientes, capazes de decidirem e atuarem na realidade socioambiental com comprometimento com a vida e com o bem-estar da sociedade [4]. Neste sentido, a compostagem surge como uma alternativa para a conscientização dos alunos e, ao mesmo tempo, uma solução para a diminuição do desperdício de matéria orgânica.

A compostagem é um processo biológico aeróbio de tratamento e estabilização de resíduos orgânicos para a produção do composto, nome dado ao fertilizante orgânico assim produzido [5]. Durante a compostagem, a matéria orgânica é decomposta, principalmente, através da ação de micro-organismos e enzimas, resultando na fragmentação gradual e oxidação dos detritos [5]. A compostagem é uma alternativa que propicia um destino útil para resíduos orgânicos através da reciclagem de material orgânico doméstico, como restos de comida, e com objetivos de produzir fertilizantes naturais que proporcionam nutrientes adequados para as plantas e auxiliam na conservação do solo [6].

O uso compostagem tem avançado, gradativamente, nos últimos anos. Mediante esses avanços, muitos autores têm explorado a compostagem como tema gerador de conhecimento na educação ambiental, Ciências Naturais e Geografia, no Ensino de Química, dentre outras aplicações [7-9]. Pádua; Tabanez [10] reiteram que a educação ambiental propicia o aumento de conhecimentos, mudança de valores e aperfeiçoamento de habilidades, condições básicas para estimular maior integração e harmonia dos indivíduos com o meio ambiente. Assim, a escola que atua na formação de cidadãos deve estar à disposição para dar suporte aos alunos e incentivá-los a realizar práticas sustentáveis. Diante deste cenário, a pesquisa desenvolvida neste trabalho, apesar de não ser, necessariamente, nova na literatura, objetiva relatar as experiências vivenciadas por um novo público alvo, de uma escola pública de ensino básico, tendo em vista que os agentes participantes do projeto necessitam de atividades em que possam por em práticas as teorias estudadas em sala de aula e, assim, sejam estimulados a discutir temas interdisciplinares relacionados ao descarte adequado do lixo e à educação ambiental.

\section{MATERIAL E MÉTODOS}

O presente trabalho foi realizado junto a uma turma de $9^{\circ}$ (nono) ano da rede pública municipal de São Miguel do Guamá, Pará, Brasil, no período de 13 de abril a 04 de novembro de 2015. Inicialmente foram selecionadas 3 turmas, em um total de 97 alunos. A turma com menor rendimento na resposta ao questionário inicial, foi selecionada para a sequência do desenvolvimento do trabalho, que de forma resumida, se deu pela identificação do ambiente, análise da quantidade de resíduos de alimentos orgânicos produzidos na escola, aplicações de questionários, aulas teóricas, coleta dos resíduos de alimentos para a prática, e por fim, diálogos com os alunos. Deste modo, foi possível inserir a turma em um programa de práticas ambientais, proporcionando a estes debates que objetivavam uma visão mais crítica sobre o desperdício de alimentos. 


\subsection{Recursos utilizados}

Para a realização deste trabalho foram necessários os seguintes materiais: folhas de papel, quadro branco, pinceis para quadro branco, lixeira, balança digital, luvas, composteira de madeira com 1 metro de largura por 1 metro de comprimento, tesoura, garrafas PET, barbantes.

\subsection{Desenvolvimento das atividades}

\section{$1^{\text {a }}$ Etapa}

Foram realizadas visitas para o reconhecimento do espaço proposto para a realização do trabalho, e também para conhecer a realidade escolar. O projeto foi apresentado a direção da escola e aos professores de ciências, em que, os mesmos se disponibilizaram a ajudar e auxiliar no que fosse necessário.

\section{$2^{\text {a }}$ Etapa}

Deu-se início a análise dos resíduos orgânicos gerados na escola no decorrer de dois turnos (manhã e tarde). Foram confeccionadas lixeiras para que fossem depositadas as sobras de alimentos provenientes da merenda escolar. Esta etapa teve a duração de uma semana. No intervalo no qual os discentes saiam para lanchar, o material era recolhido e levado para ser pesado em uma balança digital. Com base no desperdício calculado foi construída uma composteira de madeira, onde o adubo foi preparado.

\section{$3^{\text {a }}$ Etapa}

Aplicou-se um questionário a três turmas de nono ano (tratadas aqui como Turma X, Turma Y e Turma Z) do ensino fundamental na referida escola. Este foi aplicado em dias préestabelecidos com os alunos e professores. Foram aplicados 97 questionários no total com questões objetivas e subjetivas, onde os tópicos abordados foram: compostagem, práticas ambientais e educação ambiental. O objetivo desta etapa consistiu em avaliar o nível de conhecimento dos alunos a respeito dos temas e a partir disto começar a trabalhar em cima das principais carências apresentadas.

O questionário teve, também, a finalidade de auxiliar na seleção de uma turma para a aplicação do projeto. A escolha foi feita a partir da avaliação das respostas dadas pelos alunos. Desta forma, a turma escolhida foi aquela em que os alunos mostraram um menor conhecimento acerca dos assuntos.

\section{$4^{\text {a Etapa }}$}

Aplicação de uma aula teórica de 45 minutos sobre os assuntos abordados no questionário. Iniciou-se com a apresentação do projeto à turma escolhida, aonde foram abordados conteúdos básicos sobre compostagem, adubos orgânicos e inorgânicos, nutrientes necessários às plantas, fotossíntese, práticas ambientais e educação ambiental. Foi, ainda, levantado o assunto da destinação dos restos de alimentos orgânicos gerados na escola e ao final da apresentação foi mostrado que é possível utilizá-los em favor do meio ambiente.

\section{$5^{\text {a }}$ Etapa}

Nesta fase deu-se início ao processo de compostagem dos restos de alimentos gerados na escola. Os alunos da turma escolhida ficaram responsáveis de recolher os restos de alimentos após o lanche e levar para a composteira para poder ser realizado o procedimento de preparação do adubo orgânico. Esta etapa teve a duração de dois meses.

\section{$6^{\text {a Etapa }}$}

Esta etapa consistiu na montagem de uma mini horta pelos alunos da turma. Os alunos utilizaram uma garrafa pet de 2 litros para o preparo da horta. No dia seguinte, os alunos se agruparam de dois em dois para cortar as garrafas com um corte horizontal e, enchê-las, com terra preta e o adubo orgânico, proveniente da compostagem realizada na escola pelos mesmos. Após os alunos preencherem as garrafas com terra e adubo, estes plantaram sementes de cheiroverde (Coriandrum sativum) em suas respectivas garrafas e as amarraram com barbantes em uma estante cedida pela diretoria da escola. 


\section{$7^{\text {a }}$ Etapa}

A última etapa deste projeto incidiu-se na aplicação de uma aula sobre educação ambiental e compostagem para a turma nos primeiros horários do turno da manhã. A aula teve a duração de 30 minutos. Ao fim da aula foi aplicado um questionário para a avaliação do aprendizado dos discentes. A aula e o questionário foram aplicados fora da sala de aula, no local onde os mesmos fizeram o trabalho de compostagem e a horta, afim de aproximar os alunos da prática ambiental.

\section{RESULTADOS E DISCUSSÃO}

\subsection{Questionário Inicial}

O processo de avaliação teve início com aplicação de um questionário avaliativo nas três turmas de $9^{\circ}$ ano pela parte da manhã, com a finalidade de diagnosticar o conhecimento prévio dos alunos sobre compostagem, educação ambiental, reaproveitamento da matéria orgânica. De acordo com os resultados obtidos, a turma escolhida foi a Turma X, por apresentar o pior desempenho nas respostas dadas no questionário, o qual era composto por 7 questões, sendo 5 objetivas e 2 subjetivas.

Quando perguntados sobre o que é compostagem, dos 29 alunos que responderam, apenas 7 souberam responder o que seria compostagem, enquanto 22 disseram não saber. Apesar deste assunto ser uma prática bastante eficaz na promoção da educação ambiental, mostra-se pouco conhecido pelos alunos da referida turma. Desta forma, buscou-se saber: "Durante as aulas de ciências, você já participou de práticas relacionadas a educação ambiental?". Observou-se que a maioria dos alunos, exatamente 17 , respondeu que já haviam participado de práticas durante as aulas de ciências. Porém, 12 responderam que nunca tinham participado de práticas que envolvessem a educação ambiental. Santos [3] afirma que envolver os alunos no processo possibilita a difusão do pensamento reflexivo e crítico frente ao cenário ambiental atual, estimulando-os a uma participação ativa com disseminação de um conhecimento sobre a questão ambiental, que faz parte do cotidiano de cada um.

Quando indagados sobre o que é adubo orgânico, 25 alunos presentes na sala responderam saber o que é adubo orgânico e apenas 4 responderam não saber. Este fato, quando relacionado à primeira pergunta (Você sabe o que é compostagem?), revelou uma disparidade entre as respostas dadas. Os alunos, apesar de terem respondido em sua grande maioria que sabiam o que seria adubo orgânico, não sabem que este é formado a partir da compostagem.

Antes da análise da questão seguinte, vale ressaltar que durante uma semana foi quantificada a matéria orgânica gerada na escola. A partir da pesagem realizada, pôde-se obter os resultados apresentados na Tabela 1.

Tabela 1: Quantidade de alimentos desperdiçados na escola

\begin{tabular}{|l|c|c|c|}
\cline { 2 - 4 } \multicolumn{1}{c|}{} & \multicolumn{3}{c|}{ Turnos } \\
\hline \multicolumn{1}{c|}{ Dias } & Manhã & Tarde & Massa por dia \\
\hline $\mathbf{1 3 / 0 4}$ - Segunda-feira & 0,874 & 1,942 & $2,816 \mathrm{Kg}$ \\
\hline $\mathbf{1 4 / 0 4}$ - Terça-feira & 1,342 & 4,290 & $5,632 \mathrm{Kg}$ \\
\hline $\mathbf{1 5 / 0 4}$ - Quarta-feira & 0,0 & 0,689 & $0,689 \mathrm{Kg}$ \\
\hline $\mathbf{1 6 / 0 4}$ - Quinta-feira & 1,458 & 6,476 & $7,934 \mathrm{Kg}$ \\
\hline $\mathbf{1 7 / 0 4}$ - Sexta-feira & 1,768 & 2,327 & $4,095 \mathrm{Kg}$ \\
\hline \multicolumn{1}{|c|}{ Massa por turno } & $5,442 \mathrm{Kg}$ & $15,724 \mathrm{Kg}$ & $21,166 \mathrm{Kg} *$ \\
\hline
\end{tabular}

*Massa Total.

A Tabela 1 indica que no período de uma semana de funcionamento do estabelecimento de ensino, foram desperdiçados $21,166 \mathrm{~kg}$ de resíduo orgânico que seriam destinado ao lixão da cidade. Diante disso, foram abordados os seguintes questionamentos: como reaproveitar esses resíduos de alimentos? Os alunos sabem qual o destino dessa matéria orgânica? A maioria dos 
alunos (17) responderam que o lixo da escola era reaproveitado, 11 alunos responderam que não sabiam qual o destino do lixo, e apenas 1 aluno respondeu que o lixo orgânico tinha o mesmo destino dos outros lixos.

Uma das grandes preocupações no âmbito escolar, sobre a responsabilidade ambiental, gira em torno do destino dos chamados lixos orgânicos, pois sua disposição inadequada pode causar sérios danos ao meio ambiente. Em primeiro lugar, as tabulações sobre o destino do lixo nas escolas revelaram que em 2004, no Brasil, 49,3\% das escolas que promovem Educação Ambiental usavam a coleta recorrente como destino do lixo; em segundo lugar, encontram-se as escolas que incineram o lixo, com 41,3\%; e, em terceiro lugar, as escolas que jogam o lixo em outras áreas, com $11,9 \%$. O total de escolas que reutilizam ou reciclam o lixo não ultrapassa $5 \%$ [11].

A quinta pergunta era discursiva e apresentava o seguinte questionamento: É importante cuidar do meio ambiente? Justifique sua resposta! A partir das respostas dadas no questionário, todos os 29 (vinte e nove) alunos responderam que é sim, importante cuidar do meio ambiente! Porém, as respostas em sua grande maioria mostraram-se incompletas, evasivas, confusas e bastante diferentes, umas das outras.

O aluno A por exemplo:

"Sim! Por que nós não vamos adoecer através da poluição, é por isso que devemos cuidar do meio ambiente".

Enquanto isso, o aluno B respondeu da seguinte forma:

"Sim! Por que o meio ambiente é onde nós vivemos e é muito importante para nós”.

Aluno C afirmou o seguinte:

"Sim! Por que se nós não cuidarmos dele, ele vai poluir e não vai ser mais o mesmo meio ambiente de sempre".

O aluno D respondeu que:

"Sim! Cuidando do meio ambiente estamos ajudando todos os cidadãos a respirar mais saudável".

A partir destas respostas, pode-se perceber certas dificuldades dos alunos em relação às explicações, sobre o porquê da importância do cuidado para com o meio ambiente. Pôde-se observar ainda, que estes detinham apenas um vago conhecimento popular e com pouco cunho científico.

Quanto à utilização do conhecimento adquirido na escola em favor do meio ambiente, 27 alunos afirmaram que utilizam o conhecimento adquirido na escola a favor do meio ambiente, um aluno respondeu que não, e outro aluno, não respondeu. A maioria destes, afirmaram que cuidavam do meio ambiente evitando jogar lixo em locais inapropriados ou reciclando-os. Porém, nenhum aluno se referiu ao lixo orgânico, limitaram-se apenas ao lixo inorgânico, como os metais, plásticos e vidros. Isso mostra a carência de alternativas de como aplicar o conhecimento adquirido para ajudar o meio ambiente.

Quando perguntados se saberiam as consequências da disposição inadequada do lixo orgânico, 62,06 \% dos alunos que responderam o questionário (total de 18 alunos), afirmaram saber quais as consequências da disposição inadequada do lixo orgânico. Enquanto 37,94\% disseram não saber quais os danos que isto poderia causar ao meio ambiente. Assim pode-se perceber que, uma boa parte dos alunos entrevistados, tém certa noção disso, porém faltam estratégias que estimulem o senso crítico e desperte o interesse dos alunos [12]. 


\subsection{Questionário Final}

Durante o desenvolvimento das atividades os alunos mostraram-se bastante entusiasmados na execução prática do trabalho. A Figura 1 mostra a etapa em que os alunos construíram a composteira e iniciaram a observação da transformação do lixo orgânico em adubo.

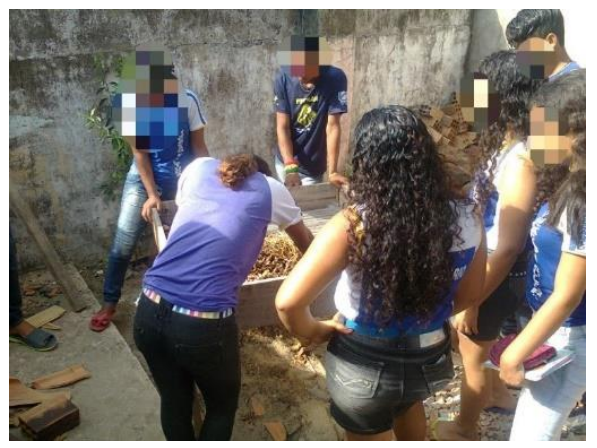

Figura 1: Composteira elaborada em madeira para transformar o lixo orgânico em adubo.

Em seguida, o adubo produzido foi inserido em garrafas PET (Figura 2) que foram utilizadas na plantação de coentro ou cheiro-verde (Coriandrum sativum), que é uma espécie que pode ser cultivado em uma ampla variedade de climas, embora não suporte temperaturas baixas e, além disso, é item muito comum na cozinha dos brasileiros.

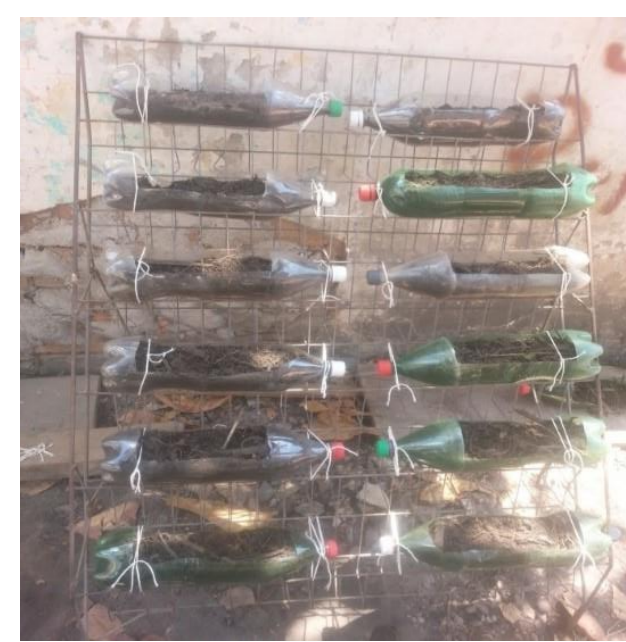

Figura 2: Horta vertical construída a partir de materiais reciclados.

Posteriormente, foi aplicado o segundo questionário com finalidade de diagnosticar os resultados obtidos após as práticas realizadas e as aulas ministradas aos alunos. Nesta etapa, estavam presentes os mesmos 29 alunos que responderam ao questionário anterior e participaram ativamente das atividades.

Vale ressaltar que alguns dos educandos fizeram perguntas adicionais:

Aluno A: "Qual tipo de adubo é melhor para ser usado em hortas?"

Aluno B: "O que não colocar na compostagem?"

Esse tipo de interação proporcionou um debate enriquecedor, aonde foi possível trabalhar diversos conteúdos, tais como: adubo orgânico e inorgânico, importância da adubação verde, como se dá o processo de compostagem e educação ambiental. Neste segundo questionário foram feitas 5 perguntas relacionadas ao tema do projeto, sendo as três primeiras objetivas e as duas últimas subjetivas.

Na primeira pergunta em que se perguntou novamente "Você sabe o que é compostagem?" $100 \%$ afirmaram que sim, que sabiam o que significava o termo. Em seguida: $E$ importante 
cuidar do meio ambiente? Justifique sua resposta! Novamente, 29 alunos responderam que é importante cuidar do meio ambiente e se observou respostas ligeiramente melhor elaboradas:

Aluno A:

"É importante sim cuidar do meio ambiente, pois com o passar dos anos, nós vamos sofrer as consequências se continuarmos tratando-o assim".

Aluno B:

"Eu acho que é importante cuidar do meio ambiente, pois é dele que tiramos os alimentos que necessitamos para sobrevivermos, se não cuidarmos, no futuro eles acabarão".

Quando perguntados: Você pretende levar o que aprendeu durante a prática para dentro de casa, mostrar para seus amigos, vizinhos e familiares? 100\% dos alunos questionados responderam que pretendem sim passar esse conhecimento adquirido neste período para outras pessoas. De acordo com Minc [13], a educação ambiental bem ensinada e bem aprendida tem de ter relação com a vida das pessoas, o seu dia a dia, o que elas veem e sentem, o seu bairro, a sua saúde, com as alternativas ecológicas. Caso contrário, torna-se artificial, distante e pouco criativa.

Na sua opinião, o que a prática realizada mudou em sua visão sobre o desperdício de matéria orgânica?

Aluno C:

"Ela mudou muitas coisas em minha vida, porque eu não sabia que restos de alimento serviam como adubo, e assim cuidar melhor do meio ambiente".

Aluno D:
"Mudou que agora em casa ou em qualquer outro lugar, sei que não devemos jogar restos de comida fora. Podemos reaproveitar para fazer adubo para as plantas".

A quinta pergunta também é discursiva e traz o seguinte questionamento: Você acha que é importante reutilizar a matéria orgânica? Por que?

Aluno E:

"É importante porque com a realização da compostagem podemos ajudar a diminuir a quantidade de lixo e ajudar o meio ambiente".

Aluno H:

"Sim, pois com a reutilização da matéria orgânica, podemos fazer adubo para as plantas, e isso servirá para nós mesmos".

É extremamente importante considerar este fato, pois, quando o lixo é destinado de maneira incorreta e fica a céu aberto, pode ocorrer contaminação de lençóis freáticos com chorume, emissão de gases do efeito estufa $\left(\mathrm{CO}_{2}, \mathrm{CH}_{4}\right.$, etc.) e, além disso, atrair animais e insetos que podem transmitir doenças ao homem. Com os trabalhos de educação ambiental por meio da compostagem, $100 \%$ dos alunos afirmaram que pretendem levar o que aprenderam durante a prática para dentro de casa, mostrar para seus amigos, vizinhos e familiares. 


\section{CONCLUSÕES}

A compostagem surge como alternativa, que pode ser realizada tanto no âmbito escolar como fora dele. A partir das análises feitas nos dois questionários foi possível observar um grande desenvolvimento dos discentes sobre os temas abordados. Assim, pôde-se perceber a importância do desenvolvimento das atividades nas turmas de ensino fundamental. Em virtude disso, pode-se inferir que essa prática constitui uma interessante abordagem no que diz respeito à prática ambiental. Após a aula e as atividades desenvolvidas na escola, percebeu-se um grande envolvimento nas atividades propostas, bem como, proporcionou aos mesmos a chance de uma atuação mais consciente no que concerne ao descarte adequado da matéria orgânica.

Tal iniciativa deve ser incentivada, não apenas no ambiente escolar, como também fora dele. A matéria orgânica gerada em excesso no ambiente escolar e a carência de práticas ambientais são duas problemáticas que necessitam ser trazidas para dentro de sala de aula. A compostagem como promotora de educação ambiental no âmbito escolar constitui uma ótima ferramenta que auxilia no aprendizado dos alunos de forma ecológica e lúdica. Por isso, pretende-se como uma das alternativas para dar sequência a este projeto, inserir um número maior de estudantes e um modelo mais complexo de composteira que acondicione uma maior quantidade destes resíduos orgânicos, afim de aproveitar a totalidade do que é gerado. Desta forma, pretende-se propiciar discussões na comunidade local sobre a coleta seletiva de lixo, prática que até o fechamento deste trabalho não era realizada no referido município.

\section{REFERÊNCIAS BIBLIOGRÁFICAS}

1. Dias GF. Educação ambiental: princípios e práticas. 9.ed. São Paulo: Gaia, 2004.

2. Baird C, Cann M. Química ambiental. $4^{a}$ ed. São Paulo: Ed. Bookman, 2011, 737 p.

3.Santos HMN, Fehr M. Educação ambiental por meio da compostagem dos resíduos sólidos orgânicos em escolas públicas de Araguari. Caminhos de Geografia. 2007 Dez;8(24):163-83

4. Medeiros AB, Mendonça MJSL, Sousa GL, OLIVEIRA IP. A Importância da educação ambiental na escola nas séries iniciais. Revista Faculdade Montes Belos. 2011 Set;4(1):1-17.

5. Bernal MP, Navarro AF, Sanchez-Monedero MA, Roig A, Cegarra J. Soil Biol. Biochem. 1998 Abr;30(3):305-313.

6. Santos BW, Gomes NR, Lima SKL, Barbosa SJA, Araújo EA. O uso da Compostagem para melhoria da agricultura familiar: Uma nova visão dos Jovens do Curso de Formação De Agentes De Desenvolvimento Rural Sustentável. I Congresso Paraibano de Agroecologia e IV Fórum Sobre o Registro Profissional do Agroecológico de Lagoa Seca- PB: UFPB, 2010.

7. Dias GF. Atividades Interdisciplinares de Educação Ambiental. Global Editora e Distribuidora Ltda, 2013.

8. Costa AP, Silva WCM. A compostagem como recurso metodológico para o ensino de ciências naturais e geografia no ensino fundamental. Enciclopédia Biosfera, centro científico conhecer. 2011 Out;7(12):1-12.

9. Silva MA, Martins ES, Amaral WK, Silva HS, Martines EAL. Compostagem: experimentação problematizadora e recurso interdisciplinar no ensino de química. Química Nova na Escola. 2015 Fev;37(1):76-81.

10. Pádua S, Tabanez M. Educação ambiental: caminhos trilhados no Brasil. São Paulo: Ipê, 1998.

11. Brasil. Ministério da Educação. Educação Ambiental: aprendizes de Sustentabilidade. Brasília - DF: Mar. 2007, p. 12,13,21.

12. Chalita G. Educação: a solução está no afeto. 6.ed. São Paulo: Gente, 2001.

13. Minc C. Ecologia e cidadania. 2. ed. reform. São Paulo, SP: Moderna, 2008. 